\title{
PRODUTIVIDADE DO CACAUEIRO EM FUNÇÃO DE CARACTERÍSTICAS DO SOLO. II. CARACTERÍSTICAS FÍSICO-MORFOLÓGICAS E ALGUNS ELEMENTOS EXTRAÍDOS PELO ATAQUE SULFÚRICO(1)
}

\author{
J . O.SOUZA J r.(2) , J .C. KER ${ }^{(3)}$,J .W. V. MELLO ${ }^{(3)} \&$ C. D. CRUZ(4)
}

\begin{abstract}
RESUMO
Com base na produtividade em sete anos (1989 a 1995) de 36 talhões produtivos de cacau, cultivados numa propriedade agrícola no sul da Bahia, foram obtidas as médi as dos três anos mais e menos produtivos, correspondendo, respectivamente, a anos de maior e menor quantidade de chuvas. Essas produtividades foram relacionadas, por análise de trilha, com as características físico-morfológicas do solo (profundidade do horizonte A; cor, porosidade, densidades aparente e de partícula dos horizontes A e B; textura das camadas de 0-20 e 30-50 cm e presença de cascalho ou pedras até à profundidade de $50 \mathrm{~cm}$ ) e com os teores totais de elementos ( $\mathrm{Ti}, \mathrm{K}, \mathrm{Cu}, \mathrm{Fe}, \mathrm{Mn}$ e Zn), obtidos pelo ataque sulfúrico, na camada de $30-50 \mathrm{~cm}$ de profundidade. Os micronutrientes extraídos pelo ataque sulfúrico foram correlacionados com aqueles extraídos pelo Mehlich-1. Em geral, as características físicas explicaram melhor a produtividade dos anos mais secos, enquanto os teores de elementos extraídos pelo ataque sulfúrico correlacionaram-se melhor com a produtividade dos anos mais chuvosos. Os talhões mais produtivos tinham horizonte A mais profundo, solo mais poroso, com maiores teores de micronutrientes catiônicos e Ti e menor teor de $\mathrm{K}$ obtido pelo ataque sulfúrico. $\mathrm{Em}$ anos mais secos, os talhões mais produtivos foram aqueles que apresentavam solo com maior teor de argila e menores teores de silte e areia. A presença de cascalho até à profundidade de $50 \mathrm{~cm}$ e a cor dos horizontes do solo não se correlacionaram significativamente com a produtividade das plantas. Cobre, $\mathrm{Mn}$ e, ou, $\mathrm{Zn}$, extraídos pelo ataque sulfúrico, indicaram solos de maior fertilidade natural em micronutrientes catiônicos para o cacaueiro.
\end{abstract}

Termos de indexação: Theobroma cacao, produtividade, características físicas, reserva de nutriente, análise de trilha.

(1) Recebido para publicação em junho de 1997 e aprovado em setembro de 1999.

(2) Professor Assistente do Departamento de Ciências Agrárias e Ambientais, Universidade Estadual de Santa Cruz. Rod. Ilhéus/ I tabuna, km 16, CEP 45650-000 IIhéus (BA). E-mail: olimpio@jacaranda.uescba.com.br.

(3) Professor Adjunto do Departamento de Solos, Universidade Federal de Viçosa - UFV. CEP 36571-000 Viçosa (MG).

(4) Professor Titular do Departamento de Biologia Vegetal, UFV. 
SUMMARY: CACAO TREE PRODUCTIVITY AS A FUNCTION OF SOIL CHARACTERISTICS. II. MORPHOLOGICAL - PHYSICAL CHARACTERISTICS AND SOME ELEMENTS EXTRACTED BY USING CONCENTRATED SULFURIC ACID

\begin{abstract}
Based on theseven year-productivities (1989 to 1995) of 36 cacao-producing areas, on a farm in southern of Bahia, Brazil, theaverage of thethremost and least productiveyears was obtained corresponding, respectively, to the highest and lowest rain availability. By path analysis, these productivities were related to both the soil morphological-physical characteristics (A-horizon depth; col or, soil and particledensities of A and B horizons; texture of soil layers at $0-20$ and $30-50 \mathrm{~cm}$ depth and the presence of gravel or stones down to a $50 \mathrm{~cm}$ depth) and the e ement contents ( $\mathrm{Ti}, \mathrm{K}, \mathrm{Fe}, \mathrm{Mn}, \mathrm{Zn}$ ) extracted from a 30-50 cm depth layer by using concentrated sulfuric acid. The micronutrients extracted by theconcentrated sulfuric acid were correlated with those extracted by Mehlich-1. Generally, the physical characteristics showed a better correlation with the drier years' productivity whereas the element contents extracted by concentrated sulfuric acid showed a better correlation with that of rainier years. Themost productiveareas werethosehaving a deeper A horizon, a soil with greater porosity, higher contents of $\mathrm{Ti}$ and cati oni c mi cronutrients, and a lower content of $K$, all extracted by concentrated sul furic acid. During thedrier years, themost productive areas were those with higher contents of clay and lower contents of silt and sand. Gravel occurrence down to $50 \mathrm{~cm}$ depth and the color of the soil horizons did not correlate significantly with plant productivy. $\mathrm{Cu}, \mathrm{Mn}$ and, or $\mathrm{Zn}$ contents, extracted by concentrated sulfuric acid, indicated soils of greater fertility in cationic micronutrients for the cacao tre.

Index terms: Thebroma cacao, productivity, physical characteristics, nutrient stock, path analysis.
\end{abstract}

\section{INTRODUÇÃO}

O cacaueiro (Theobroma cacao L.) é cultivado há milhares de anos no continente americano. Os astecas e os incas apreciavam a bebida derivada de seu fruto, muito antes de Colombo descobrir o N ovo Mundo. A importância do cacaueiro era tanta, que atribuíam a ele origem divina e sua plantação era, muitas vezes, cercada de cerimônias religiosas. A amêndoa circul ou comercialmente como moeda eseu consumo era um luxo, ficando restrito basicamente aos senhores enobres (Bondar, 1938). Para o estado da Bahia, o cacau é o principal produto agrícola ejá representou de 40 a $50 \%$ das suas exportações, contribuindo com cerca de $50 \%$ da composição de suas receitas (Gramacho et al., 1992).

As propriedades eas características físicas dosolo revestem-se de importância capital no cultivo de planta perene, como o cacaueiro, principalmente quando associadas ao volume e distribuição das chuvas (Ahenkorah, 1981). Elas influem na capaci dade de retenção de água e drenagem do solo, bem como na profundi dade de penetração do sistema radicular (Braudeau, 1970), além de influenciar as reações químicas e a absorção de nutrientes pela planta.

A ocorrência de "piçarra", termo popular utilizado nas regiões produtoras de cacau do Brasil para designar presença de maior quantidade de cascal ho aolongo do perfil dosolo, dificulta o desenvol vimento do sistema radicular da planta. Por isto, Garcia et al. (1985) consideram profundidade efetiva mínima de $1,20 \mathrm{~m}$ para o cultivo do cacaueiro, enquanto Gramacho et al. (1992) recomendam que até à profundidade de $80 \mathrm{~cm}$ não deva ocorrer "piçarra" nem camada impermeável.

A parentemente, os fatores físicos que afetam o espaço radicular, conferindo maior resistência mecânica ao solo, contribuem expressivamente para reduzir a produtividade do cacaueiro (Cadima Z. \& Alvim, 1973).

O cacaueiro é encontrado em solos com as mais diferentes texturas. Contudo, seu cultivo só é indicado para solos arenosos, quando as adubações são parceladas e balanceadas, e para regiões com precipitação pluvial elevada e bem distribuída ao longo do ano. Em regiões com períodos de escassez de chuva, os solos argilosos e bem estruturados seriam os mais indicados (Hardy, 1960; Braudeau, 1970; Garcia, 1985).

Dentre os aspectos morfológicos, a coloração do solo reveste-se de grande importância no processo natural deavaliação, pois reflete, em termos gerais, o teor de matéria orgânica, o tipo de óxido de ferro predominantee a drenagem do perfil, dando, assim, uma idéia geral do pedoambiente e da fertilidade 
dos solos (Carmo et al., 1990). Contudo, a cor, apesar de ser uma característica de fácil avaliação e de refletir uma série deatributos dosolo, nãonecessariamente correlaciona-se com a produtividade do solo (Lepsch et al., 1991), pois, às vezes, não retrata limitações ou excessos específicos presentes no solo. Para a cultura do cacau, Hardy (1960) destaca que sol os com horizonteB bruno-avermel hado, vermelho ou vermel ho-amarelado seriam os mais indicados do que os de col oração pálida, cinzenta ou branca, pois, de modo geral, apresentam maior concentração de nutrientes e são bem drenados.

No Brasil, o método do ataque sulfúrico vem sendo empregado por mais de meio século em trabalhos de pedologia, sendo determinante na diferenciação de classes do sistema brasileiro de classificaçãoo (Camargo et al., 1987; Oliveira et al., 1992). Além disto, ele permite quantificar espécies mineralógicas (Resendeet al., 1987) e pode também fornecer informações sobre a reserva potencial de al guns el ementos no solo (Curi \& Fransmeier, 1987; Resendeet al., 1987; Ker, 1995). A pesar detoda essa potencialidade, os resultados do ataquesulfúrico vêm sendo empregados, quase que exclusivamente, em trabal hos pedológi cos de classificação, sobretudo pelo fato de, ultimamente, só serem dosados silício, Al, $\mathrm{Fe}$ e $\mathrm{Ti}$. Como a produtividade e o conteúdo de nutrientes em determinada cultura, principalmente perene, nem sempre se correlacionam com os teores de al guns el ementos disponíveis (Melo et al., 1995), faz-se necessário correlacionar outros métodos, que não os de rotina, com a produtividade.

O objetivo deste trabalho foi relacionar produtividades de anos mais e menos chuvosos de 36 tal hões produtores de cacau, de uma propriedade no sul da Bahia, com características físicomorfológicas e com el ementos químicos obtidos pelo ataque sulfúrico.

\section{MATE RIAL E MÉTODOS}

Esteestudo foi desenvolvidona Fazenda Oceania, pertencente à empresa Mendonça Agropecuária Ltda, no município de I tagibá (BA). Sel ecionaramse 36 tal hões, com média de 5,0 ha, 920 plantas/ha, 95\% de plantas "produtivas" (acima de sete anos de idade), com o predomínio de uma unidade de solo por talhão e pequena ou nenhuma presença de plantas que apresentassem comprovadamente problemas genéticos (cacaueiros auto-intercompatíveis de grande vigor vegetativo). A produtividadeanual decada um dos 36 talhões, dos anos de1989 a 1995, foi estimada pela divisão da produção pel o número de plantas produtivas de cada tal hão e ano.

Maiores produtividades do cacaueiro são verificadas em anos mais chuvosos (Almeida, 1986;
Alvim, 1988; Scerne, 1988). Por isto, dos sete anos deste estudo, utilizaram-se as médias das três maiores e das três menores produtividades anuais de cada tal hão, ou seja, condições de maior e menor quantidade de chuva, respectiva-mente (Souza J r., 1997).

Retiraram-se 20 amostras simples de solo por talhão, nas profundidades de $0-20$ e $30-50 \mathrm{~cm}$, que foram homogeneizadas, secas ao ar, peneiradas $(\phi=2,0 \mathrm{~mm}$ ) e caracterizadas quanto à textura, com dispersão em NaOH 0,5 mol L-1 (Moura Filho, 1964).

Durante o processo de tradagem, verificou-se a existência de pedras ou cascal hos ao longo do perfil, indicadores de possível impedimento físico, até à profundidade máxima amostrada. Observada a presença desse possível impedimento, anotou-se a profundidade em que ele ocorria; caso contrário, considerou-se que não havia impedimento até $50 \mathrm{~cm}$ de profundidade. Com os dados das 20 observações por talhão, calculou-se a profundidade média da ocorrência de pedras e cascal hos até os $50 \mathrm{~cm}$. Essa variável foi denominada de "profundidade efetiva aparente até $50 \mathrm{~cm}$ " $\left(\mathrm{PEA}_{50}\right)$.

As amostras compostas de terra fina seca ao ar, da profundidade de $30-50 \mathrm{~cm}$, foram submetidas ao ataquesulfúrico(EMBRAPA, 1997). Noextratoácido, foram dosados FeeTi, conforme EMBRAPA (1997); $\mathrm{K}$, por fotometria de chama, e $\mathrm{Cu}, \mathrm{Mn}$ e $\mathrm{Zn}$, por espectrofotometria de absorção atômica.

Em cada talhão, abriu-se uma trincheira com a finalidade deavaliar a profundidade do horizonte $A$ e a cor, por intermédio de Carta de Munsell, dos horizontes A e B. Com o auxílio de anel vol umétrico, retiraram-se duas amostras de solo em cada horizonte, para determinação das densidades aparentes e de partículas (EMBRAPA, 1997).

Para transformar a cor em um fator quantitativo, utilizou-se o índice de vermel ho (IV = (10 - Matiz) $\mathrm{x}$ Croma $\div$ Valor), proposto por Torrent et al. (1980), e fator devermelho $(\mathrm{FV}=(10-$ Matiz $)+($ Croma $\div$ Valor $))$, sugerido por Santana (1984).

Cada produtividade (média das máximas e média das mínimas) foi considerada comovariável principal na análise de trilha. As variáveis explicativas (independentes) foram separadas em dois grupos: características da camada superficial (profundidade, cor, densidades e porosidade do horizonte A, PEA $A_{50}$ e textura da camada de $0-20 \mathrm{~cm}$ ) e da camada subsuperficial (cor, densidades e porosidade do horizonte $\mathrm{B}$, textura e teor de el ementos do ataque sulfúrico da camada de $30-50 \mathrm{~cm}$ ). Quando duas variáveis independentes apresentaram el evada colinearidade ( $r>0,80)$, uma delas foi excluída da análise, optando-se por manter aquela que gerou o modelo com maior coeficiente de determinação. Final mente, foram aceitas as variáveis cujos efeitos diretos apresentaram significância até $10 \%$. 


\section{RESULTADOSE DISCUSSÃO}

Nos tal hões estudados nestetrabal ho, observaramse diferentes materiais de origem dos solos. Foram identificadas as seguintes rochas: granito, gnaissee gnaisse-anfibolítico. A associação do material de origem à posição do solo na paisagem (relevo e altitude) possibilitou a formação de ampla variação de solos: Latossolos Vermelho-Amarelo, solos com horizonte $\mathrm{B}$ textural e Cambissolos. Os Podzólicos formavam a classe de solo de maior domínio.

A produtividade média dos três anos mais produtivos (mais chuvosos) e dos três anos menos produtivos (mais secos) variou de 1.447 a 2.675 e de 705 a $1.976 \mathrm{~kg}$ por 1.000 plantas produtivas, respectivamente. Nos três anos mais chuvosos, a precipitação entre março e fevereiro, período de 12 meses de chuva que mais se correlacionou com a produção anual de cacau da lavoura em estudo (Souza J r., 1997), variou de 1.136 a 1.590 mme, nos três anos mais secos, de 723 a $897 \mathrm{~mm}$.

No quadro 1, são dados os valores médios, máximos e mínimos das características físicas avaliadas na superfície (horizonte A ou camada de 0-20 cm) e na subsuperfície (horizonte B ou camada de 30-50 cm). Observa-se ampla variação da espessura do horizonte $A$, da densidade e porosidade dos horizontes e da textura dos solos dos talhões. Percebeu-se também grande variação entre os el ementos dosados no extrato do ataque sulfúrico, em especial para K, Cu e Mn (Quadro 2).

Os baixos coeficientes de determinação encontrados indicam que as características físicas avaliadas na superfície explicaram pouco a produtividade do cacaueiro. Tais características tiveram maior relação com a profundidade dos anos
Quadro 2. Teores médios, mínimos e máximos de elementos extraídos pelo ataque sulfúrico, na terra fina seca ao ar, na camada de $30-50 \mathrm{~cm}$, de 36 talhões de cacau

\begin{tabular}{|c|c|c|c|c|c|c|}
\hline Valor & $\mathrm{Fe}_{2} \mathrm{O}_{3}$ & $\mathrm{TiO}_{2}$ & $\mathbf{K}$ & $\mathrm{Cu}$ & Mn & $\mathbf{Z n}$ \\
\hline & \multicolumn{2}{|c|}{$-\mathrm{g} \mathrm{kg}^{-1}-$} & \multicolumn{4}{|c|}{$\mathrm{mg} \mathrm{kg}^{-1}$} \\
\hline Médio & 50 & 8,8 & 881 & 13,2 & 179 & 39,6 \\
\hline Mínimo & 14 & 3,5 & 303 & 0,5 & 31 & 11,5 \\
\hline Máximo & 89 & 13,2 & 4.267 & 28,8 & 549 & 57,0 \\
\hline
\end{tabular}

mais secos do que com a dos anos mais chuvosos (Quadro 3), fato também observado na subsuperfície (Quadro 4).

Na subsuperfície, onde se avaliaram simultaneamente características físicas e derivadas do ataque sulfúrico, foram observados mel hores coeficientes de determinação (Quadro 4) do que quando analisadas apenas as características físicas da superfície (Quadro 3).

Os valores absolutos dos efeitos, direto e total, bem como suas significâncias, indicam que a produtividade dos anos mais chuvosos se correlacionou melhor com as variáveis químicas (elementos extraídos pelo ataque sulfúrico) do que com as variáveisfísicas avaliadas na subsuperfície(Quadro 4).

Independentemente da disponibilidade de água, os tal hões mais produtivos foram os de horizonte $A$ mais poroso. Todavia, sua espessura teve efeitos, direto e total, significativos apenas sobre a produtividade dos anos mais chuvosos (Quadro 3).

Quadro 1. Valores médios, mínimos e máximos das características físico-morfológicas ${ }^{(1)}$, avaliadas na camada de 0-20 cm (ou horizonte A) e de $30-50 \mathrm{~cm}$ (ou horizonte B) do solo de 36 talhões de cacau

\begin{tabular}{|c|c|c|c|c|c|c|c|c|c|c|c|}
\hline Valor & PEA50 & ESPA & IV & FV & DA & DP & Po & AG & AF & Silte & Argila \\
\hline & \multicolumn{2}{|c|}{$-\mathrm{cm}-$} & & & \multicolumn{2}{|c|}{$-\mathrm{kg} \mathrm{dm}^{-3}$} & $\%$ & \multicolumn{4}{|c|}{$\mathrm{g} \mathrm{kg}^{-1}$} \\
\hline \multicolumn{12}{|c|}{ Camada de $0-20 \mathrm{~cm}$ ou horizonte $A$} \\
\hline Médio & -- & 17 & 0,0 & 0,8 & 1,44 & 2,58 & 44 & 420 & 220 & 100 & 260 \\
\hline Mínimo & -- & 05 & 0,0 & 0,6 & 1,24 & 2,47 & 33 & 190 & 130 & 30 & 110 \\
\hline Máximo & -- & 40 & 0,0 & 1,3 & 1,75 & 2,67 & 52 & 570 & 350 & 180 & 560 \\
\hline \multicolumn{12}{|c|}{ Camada de $30-50 \mathrm{~cm}$ ou horizonte B } \\
\hline Médio & 46 & -- & 2,5 & 3,2 & 1,46 & 2,65 & 45 & 330 & 180 & 110 & 380 \\
\hline Mínimo & 36 & -- & 0,0 & 0,6 & 1,21 & 2,56 & 32 & 170 & 110 & 40 & 140 \\
\hline Máximo & 50 & -- & 9,6 & 8,5 & 1,78 & 2,73 & 56 & 500 & 270 & 280 & 640 \\
\hline
\end{tabular}

(1) Profundidade efetiva aparente até $50 \mathrm{~cm}\left(\mathrm{PEA}_{50}\right)$; espessura do horizonte A (ESPA); índice de vermel ho (IV), fator de vermelho (FV), densidade aparente (DA), densidade de partícula (DP) e porosidade (Po) dos horizontes; e teor de areia grossa (AG), areia fina (AF) nas camadas. 
Quadro 3. Desdobramentos das correlações em efeitos di retos e indiretos ${ }^{(1)}$, entre a produtividade média do cacauei ro e características físicas da superfície do solo (camada de $0-20 \mathrm{~cm}$ ou do horizonte A) de 36 talhões de cacau

\begin{tabular}{|c|c|c|c|}
\hline Variável & Espessura do A & Porosidade do A & Total(2) \\
\hline \multicolumn{4}{|c|}{ Considerando a média das maiores produtividades (anos mais chuvosos) } \\
\hline $\begin{array}{l}\text { Espessura do A } \\
\text { Porosidade do A }\end{array}$ & $\frac{0,29 *}{-0,01}$ & $\begin{array}{l}-0,01 \\
\underline{0,30 *}\end{array}$ & $\begin{array}{l}0,28^{*} \\
0,29 *\end{array}$ \\
\hline \multicolumn{4}{|c|}{$\mathrm{R}^{2}=0,17^{*}$; efeito da variável residual $=0,91$} \\
\hline & Porosidade do A & Silte de $0-20 \mathrm{~cm}$ & Total(2) \\
\hline \multicolumn{4}{|c|}{ Considerando a média das menores produtividades (anos mais secos) } \\
\hline $\begin{array}{l}\text { Porosidade do A } \\
\text { Silte de } 0-20 \mathrm{~cm}\end{array}$ & $\frac{0,32 *}{0,04}$ & $\begin{array}{l}-0,06 \\
-0,42 * *\end{array}$ & $\begin{array}{c}0,26^{\circ} \\
-0,38^{*}\end{array}$ \\
\hline$R^{2}=0,24 *$; efeito &, 87 & & \\
\hline
\end{tabular}

Quadro 4. Desdobramentos das correlações em efeitos diretos e indiretos ${ }^{(1)}$, entre a produtividade média do cacauei ro e características físi cas da subsuperfície do solo (camada de $30-50 \mathrm{~cm}$ ou do horizonte B) e teores de alguns elementos extraídos pelo ataque sulfúrico (camada de $30-50 \mathrm{~cm}$ ), de 36 talhões de cacau

\begin{tabular}{|c|c|c|c|c|}
\hline Variável & Areia grossa de $30-50 \mathrm{~cm}$ & $\mathbf{K}$ & Mn & Total(2) \\
\hline \multicolumn{5}{|c|}{ Considerando a média das maiores produtividades (anos mais chuvosos) } \\
\hline $\begin{array}{l}\text { Areia grossa de } 30-50 \mathrm{~cm} \\
\mathrm{~K} \\
\mathrm{Mn}\end{array}$ & $\begin{array}{l}-0,36 * \\
0,13 \\
-0,08\end{array}$ & $\begin{array}{l}0,20 \\
-\underline{0,58^{*}} \\
0,04\end{array}$ & $\begin{array}{l}0,10 \\
-0,03 \\
\underline{0,43}^{* *}\end{array}$ & $\begin{array}{l}-0,08 \\
-0,26^{\circ} \\
0,42^{* *}\end{array}$ \\
\hline \multicolumn{5}{|c|}{$R^{2}=0,31 * ;$ efeito da variável residual $=0,83$} \\
\hline & Porosidade do B & Silte de $30-50 \mathrm{~cm}$ & $\mathbf{Z n}$ & Total(2) \\
\hline \multicolumn{5}{|c|}{ Considerando a média das menores produtividades (anos mais secos) } \\
\hline Porosidade do B & $\underline{0,21^{\circ}}$ & 0,11 & 0,05 & $0,37 *$ \\
\hline Silte de $30-50 \mathrm{~cm}$ & $-\overline{0,07}$ & $-\underline{0,33 *}$ & $-0,06$ & $-0,46 * *$ \\
\hline $\mathrm{Zn}$ & 0,04 & $\overline{0,07}$ & $\underline{0,28 *}$ & $0,39 * *$ \\
\hline
\end{tabular}

(1) Leituras dos efeitos diretos na diagonal (sublinhado) e dos efeitos indiretos na horizontal. ${ }^{(2)}$ Coeficiente de correlação linear simples ( $r$ ). **, * e ${ }^{\circ}$ significativos a 1, 5 e $10 \%$, respectivamente, pelo teste $\mathrm{F}$.

A maior porosidade do horizonte B também favoreceu o aumento da produtividade dos anos mais secos (Quadro 4). Cadima Z. \& Alvim (1973) não encontraram qualquer correlação da porosidade ou da densidades do solo com a produtividade do cacaueiro.

É válido ressaltar que, como a densidade de partícula variou pouco (Quadro 1), a porosidade apresentou alta co-variância com a densidade aparente, ou seja, horizontes mais porosos seriam sinônimos de horizontes menos densos, e mais propíci os para o desenvolvimento do cacaueiro (Yaw, 1981).

Para os anos mais chuvosos, a textura da camada de 0-20 cm não apresentou efeitos, direto ou total, significativos $(p>0,10)$ sobre a produtividade. J á a areia grossa da camada de $30-50 \mathrm{~cm}$ apontou efeito direto, significativo e negativo, nas maiores produtividades (Quadro 4). Correia (1993), trabalhando 
com análise de trilha, concluiu que, dentre as características físicas avaliadas, as que mais prejudicaram a produtividade do eucali pto foram os teores de areia grossa e areia fina na profundidade de $90-110 \mathrm{~cm}$.

Para os anos mais secos, os solos mais siltosos, tanto na superfície (Quadro 3) quanto na subsuperfície (Quadro4), foram os menos produtivos, possivel mente por apresentarem menor agregação, menor capacidade de retenção de água e maiores impedimentos físicos que dificultam o desenvolvimento normal do sistema radicular. Isto indica que, diferentemente do sugerido por Garcia et al. (1985), os solos mais siltosos não seriam apropriados para o cultivo do cacaueiro, em regiões sujeitas a estiagens.

Além do silte, outras frações do solo, apesar de não apresentarem efeitos diretos significativos $(p>0,10)$, correlacionaram-se significativamente com a produtividade do cacaueiro nos anos mais secos: areia fina da superfície $(r=-0,28, p<0,10)$ e argila $(r=0,25, p<0,10)$ eareia fina da subsuperfície ( $r=-0,26, p<0,10)$. I sso confirma que solos mais argil osos são mais indicados para regiões sujeitas à escassez de chuvas (Braudeau, 1970). Cadima Z. \& Alvim (1973) não encontraram correlações significativas entre a produtividade média de três anos, de 14 propriedades de cacau, com o teor de argila dos horizontes A e B, porém constataram correlação significativa e negativa entre o teor de argila no horizonte $\mathrm{C}$ ea produtividade. Esses autores al ertam que a menor aeração do sol o pode ser a causa dessa correlação, de modo que esses resultados podem ter sido obtidos em anos mais chuvosos, em que a maior quantidade de argila poderia estar dificultando a drenagem do solo. O teor médio deargila do horizonte C encontrado por esses autores, $480 \mathrm{~g} \mathrm{~kg}^{-1}$, foi superior ao médio determinado neste trabalho, na profundidade de $30-50 \mathrm{~cm}$, que foi de $380 \mathrm{~g} \mathrm{~kg}^{-1}$.

A cor do solo não se apresentou como uma boa característica para identificar áreas de cacau com diferentes potenciais produtivos. O índice e o fator de vermelho não apresentaram efeitos, direto ou total, significativos $(p>0,10)$ sobreas produtividades.
No horizonte A, esse fato se deve ao maior teor de matéria orgânica, cujo poder pigmentante nesses solos homogeneiza sua coloração para cores mais escuras. No horizonte B, $72 \%$ dos perfis analisados apresentaram matizes entre 10 YR e 7,5 YR, revelando também uma pequena distinção da cor, com predomínio do vermel ho-amarelado.

Independentementeda produtividadeconsiderada, a PEA $A_{50}$, variável que reflete a profundidade de ocorrência de pedras ou cascal ho ao longo do perfil do solo até à profundidade de $50 \mathrm{~cm}$, não foi uma característica essencial para explicar as diferenças de produtividades. Tantoseu efeito direto quanto sua correlação linear simples com a produtividade não foram significativos $(p>0,10)$.

O manganês extraído pelo ataque sulfúrico correlacionou-se positiva e significativamente com a produtividade dos anos mais chuvosos (Quadro 4). Outros micronu-trientes catiônicos e o Ti também apresentaram correlaçãolinear simples significativa com a média das maiores produtividades: 0,49 $(p<0,01)$ para o Zn, 0,37 ( $<<0,05)$ para o Ti, 0,33 $(p<0,05)$ para o Cu e 0,31 ( $p<0,05)$ para oFe.

Nos anos mais secos, o $\mathrm{Zn}$ do ataque sulfúrico mostrou correl ação significativa com a produtividade (Quadro 4). Outros elementos do ataque sulfúrico também apresentaram correl ação linear simples, positiva e significativa, com a média das menores produtividades: 0,34 ( $p<0,05)$ para o Fe, 0,28 $(p<0,05)$ para oTi e 0,27 ( $p<0,10)$ para o $\mathrm{Cu}$.

$A$ afinidade geoquímica entre esses elementos é alta (Chesworth, 1991; Alloway, 1993; Ker, 1995), ou seja, a co-variância entre eles é al ta e, conseqüentemente, alta correlação de um deles com a produtividade não necessariamente indica que haja uma relação direta entre o teor do referido el emento e a produtividade. Essa afinidade geoquímica é confirmada pelas correlações observadas entre os teores de $\mathrm{Cu}, \mathrm{Fe}, \mathrm{Mn}, \mathrm{Zn}$ e Ti do ataque sulfúrico (Quadro 5). Destes el ementos, apenas a correlação entre o $\mathrm{Fe}$ e o $\mathrm{Mn}$ mostrou-se não-significativa (Quadro 5).

Quadro 5. Coeficientes de correlação linear simples ( $r$ ) entre alguns elementos extraídos pelo ataque sulfúrico (AS) e, desses, com micronutrientes extraídos pelo Mehlich-1 (M1), na terra fina seca ao ar, na camada de $30-50 \mathrm{~cm}$, de 36 talhões de cacau

\begin{tabular}{|c|c|c|c|c|c|c|c|c|c|}
\hline & $\mathbf{T} \mathbf{i}_{\text {AS }}$ & $C u_{A S}$ & $M n_{A S}$ & $\mathbf{Z n}_{\mathrm{AS}}$ & $K_{\text {AS }}$ & $F e_{M 1}$ & $\mathrm{Cu}_{\mathrm{M1}}$ & $\mathrm{Mn}_{\mathrm{M1}}$ & $\mathbf{Z n}_{\mathrm{M1}}$ \\
\hline $\mathrm{Fe}_{\mathbf{A S}}$ & $0,54 * * *$ & $0,53 * * *$ & $0,16^{\text {ns }}$ & $0,53^{* * *}$ & $-0,25^{\circ}$ & $-0,69 * * *$ & $0,04^{\text {ns }}$ & $-0,12^{\mathrm{ns}}$ & $-0,19$ ns \\
\hline $\mathrm{Ti}_{\mathbf{A S}}$ & & $0,63^{* * *}$ & $0,46^{* *}$ & $0,65^{* * *}$ & $-0,39 * *$ & $-0,23^{\circ}$ & $0,46 * *$ & $0,29 *$ & $0,16^{\mathrm{ns}}$ \\
\hline $\mathrm{Cu}_{\mathbf{A S}}$ & & & $0,67 * * *$ & $0,83^{* * *}$ & $-0,22^{\circ}$ & $-0,29 *$ & $0,78^{* * *}$ & $0,56 * * *$ & $0,23^{\circ}$ \\
\hline $\mathrm{Mn}_{\mathbf{A S}}$ & & & & $0,68 * * *$ & $-0,06^{n s}$ & $-0,16^{n s}$ & $0,78 * * *$ & $0,72 * * *$ & $0,24^{\circ}$ \\
\hline $\mathrm{Zn}_{\mathrm{AS}}$ & & & & & $-0,50 * *$ & $-0,25^{\circ}$ & $0,74 * * *$ & $0,56 * * *$ & $0,46 * *$ \\
\hline
\end{tabular}

***, **, * e ${ }^{\circ}$ significativos a 0,$1 ; 1 ; 5$ e 10\%, respectivamente. 
O cobre, o manganês e ozinco do ataque sulfúrico, além de se correl acionarem significativamenteentre si, também apresentaram correlações significativas com suas formas disponíveis, extraídas pel o Mehlich-1 (Quadro 5). Conseqüentemente, qual quer um desses três nutrientes, dosados no extrato do ataque sulfúrico, poderia ser utilizado em avaliação conjunta da fertilidade do solo nesses três micronutrientes. É válido ressaltar que não foi feita adubação com micronutrientes em nenhum tal hão estudado.

No quadro 5, outra correlação que chama atenção éa entrea forma deF e extraí do pel o ataque sul fúrico e pelo Mehlich-1, que é elevada, porém com sinal negativo, indicando uma relação inversa entre as duas formas de Fe no solo. Isto pode ser entendido da seguinte forma: sol os mais ricos em Fe total têm esse elemento predominantementena forma oxidada (Besoain, 1985), debaixíssima sol ubilidade (Lindsay, 1979), enquanto os sol os que estão sujeitos à redução têm maior teor de Fe solúvel, o qual pode ser gradativamente removido do solo e, conseqüentemente, diminuir o teor total Fe. Vários trabalhos, como os de Mello et al . (1992); Borges J r. et al. (1998), suger em que a solução de M ehlich-1 extrai parte do Fe amorfo dos solos, considerando a ocorrência de maiores teores de Fe extraído pelo Mehlich-1 em solos com alta relação $\mathrm{F} \mathrm{e-oxalato/F} \mathrm{e-ditionito.}$

Observaram-se correlações significativas e negativas entre os teores de K e os teores de Zn, Ti, FeeCu determinados no ataquesulfúrico (Quadro 5). O potássioé um elemento mais abundanteem rochas áci das, ricas em fel dspatos deK e micas, eem al guns materiais retrabalhados, ricos principalmente em muscovita. Conseqüentemente, solos pobres em minerais ferromagnesianos têm, geralmente, menores teores de $\mathrm{Ca}, \mathrm{Mg}, \mathrm{P}$ e el ementos traço (Mason, 1971; Minette, 1985; Alloway, 1993). Tal observação auxiliaria entender a correlação significativa enegativa entreo $\mathrm{K}$ coma produtividade dos anos mais chuvosos (Quadro 4). Meloet al. (1995), estudando formas de K, em horizontes de oito solos do Rio Grande do Sul, não encontraram correlação significativa entre o potássio do ataque sulfúricoea produtividade deeucalipto, porém verificaram alguma correlação com o conteúdo de K nos componentes da parte aérea. As mel hores correlações, verificadas por esses autores entre produtividade ou conteúdo do nutriente na planta, foram com o K não trocável, extraído com ácido nítrico a quente.

\section{CONCLUSÕES}

1. Demodogeral, os fatores físicos correlacionaramse mel hor com a produtividade dos anos mais secos, enquanto os el ementos obtidos pel o ataque sulfúrico correlacionaram-se mel hor com a produtividade dos anos mais chuvosos.
2. Dentre os fatores físicos estudados, a espessura do horizonte $A$ e a porosidade do solo influíram na produtividade do cacaueiro. Nos anos mais secos, os tal hões com sol os de textura mais fina foram os mais produtivos.

3. Os solos mais ricos em micronutrientes catiônicos e Ti e mais pobres em K, extraídos pelo ataque sulfúrico, foram os mais produtivos. O teor dequalquer um dos elementos $\mathrm{Cu}, \mathrm{Mn}$ ou $\mathrm{Zn}$, extraível pelo ataque sulfúrico, mostrou-se bom indicador da fertilidade natural dos solos no que se refere a micronutrientes catiônicos para o cacaueiro.

4. A presença de cascalho ou pedras até à profundidade avaliada $(50 \mathrm{~cm})$ ea cor dos horizontes do solo não se correlacionaram significativamente com a produtividade das plantas.

\section{LITE RATURA CITADA}

AHENKORAH, Y. The influence of environment on growth and production of the cacao tree: soils and nutrition. In: CONFERENCE INTERNACIONALE SUR LA RECHERCHE CACAOYERE, 7., Douala, 1979. Actes. Lagos, Cocoa Producers' Alliance, 1981. p.167-176.

ALLOWAY, B.J. The origins of heavy metals in soils. In: ALLOWAY, B.J ., ed. Heavy metals in soils. London, Blackie Academic \& Professional, 1993. p.29-39.

ALMEIDA, H.A. Influência de elementos meteorológicos no lançamento foliar, na floração e frutificação do cacaueiro (Theobroma cacao L.). Piracicaba, Escola Superior de Agricultura Luiz de Queiroz, 1986. 111p. (Tesede Mestrado)

ALVIM, P.T. Relações entre fatores climáticos e produção do cacaueiro. In: CONFERENCIA INTERNATIONAL DE INVESTIGACIÓN EM CACAO, 10., Santo Domingo, 1987. Actas. Lagos, Cocoa Producers' Alliance, 1988. p.159-167.

BESOAIN, E. Mineralogía de arcilas de suelos. San J osé, IICA, 1985. 1216p.

BONDAR, G. A cultura de cacao na Bahia. São Paulo, Revista dos Tribunaes, Instituto de Cacao da Bahia, 1938. 205p.

BORGESJ r., M.; MELLO, J .W.V; RIBEIRO, A.C. \& SOARES, P.C. Avaliação de critérios para calagem de arroz inundado em casa de vegetação. R. Bras. Ci. Solo, 22:281-289, 1998.

BRAUDEAU, J . El cacao. Traducción: HERNÁNDEZCARDONA, A.M. Barcelona, Blume, 1970. 297p.

CADIMA Z., A. \& ALVIM, P.T. Algunos factores del suelo asociados con la productividad del cacaotero en Bahia, Brazil. R. Theobroma, 3:13-26, 1973.

CAMARGO, M.N; KLAMT, E.\& KAUFFMAN, J .H. Classificação de solos usada em levantamentos pedológicos no Brasil. Campinas, B. Inf. SBCS, 12:11-33, 1987.

CARMO, D.N.; RESENDE, M. \& SILVA, T.C.A. Avaliação da aptidão das terras para eucalipto. In: BARROS, N.F. \& NOVAIS, R.F., eds. Relação sol o-eucalipto. Viçosa, Fol ha de Viçosa, 1990. p.187-235. 
CHESWORTH, W. Geochemistry of micronutrients. In: MORTVEDT, J .J .; COX, F.R.; SHUMAN, L.M. \& WELCH, R.M., eds. Micronutrients in agriculture. 2.ed. Madison, Soil Science Society of America, 1991. p.1-30.

CORREIA, J .R. Uso detécnicas multivariadas no estudo das interrelações de características do solo e a produtividade de eucalipto. Viçosa, Universidade Federal de Viçosa, 1993. 106p. (Tese de Mestrado)

CURI, N. \& FRANSMEIER, D.P. Effect of parent rocks on chemical and mineralogical proprerties of some oxisols in Brazil. Soil Sci. Soc. Am. J ., 51:153-158, 1987.

EMPRESA BRASILEIRA DE PESQUISA AGROPECUÁRIA EMBRAPA. Serviço Nacional de Levantamento e Conservação dos Solos. Manual de métodos de análise do solo. Rio de J aneiro, 1997. 212p.

GARCIA, J J .S.; MORAIS, F.I.O.; ALMEIDA, L.C. \& DIAS, J .C. Sistema de produção do cacaueiro na amazônia brasileira. Belém, CEPLAC/DEPEA, 1985. 118p.

GRAMACHO, I.C.P.; MAGNO, A.E.S.; MANDARINO, E.P. \& MATOS, A. Cultivo e beneficiamento do cacau na Bahia. Ilhéus, CEPLAC, 1992. 124p.

HARDY, Cacao manual. Turrial ba, I nter-American I nstitute of Agricultural Sciences, 1960. 395p.

KER, J.C. Mineralogia, sorção e dessorção de fosfato, magnetização e elementos traços de Latossolos do Brasil. Viçosa, U niversidade F ederal de Viçosa, 1995. 181p. (Tese de Doutorado)

LEPSCH, I.F.; BELLINAZZI J r., R.; BERTOLINI, D. \& ESPÍNDOLA, C.R. Manual para levantamento utilitário do meio físico e classificação de terras no sistema de capacidade de uso. 4a aproximação, Campinas, Sociedade Brasileira de Ciência do Solo, 1991. 175p.

LINDSAY, W.L. Chemical equilibrium in soils. New York, J ohn Wiley \& Sons, 1979. 449p.

MASON, B. Princípios de geoquímica. Tradução de FRANCO, R.R. São Paulo, Polígono, 1971. 381p.
MELLO,J .W.V; FONTES, M.P.F.; RIBEIRO, A.C.\&ALVAREZV., V.H. I nundação e calagem em sol os de várzea: I. Alterações de $\mathrm{pH}$, Eh e teores de $\mathrm{Fe}^{2+}$ e $\mathrm{Mn}^{2+}$ em solução. R. Bras. Ci. Solo, 16:309-317, 1992.

MELO, V.F.; BARROS, N.F.; COSTA, L.M.; NOVAIS, R.F. \& FONTES, M.P.F. Formas de potássio e de magnésio em solos do Rio Grande do Sul, e sua relação com o conteúdo na planta e com a produção em plantios de eucalipto. R. Bras. Ci. Solo, 19:165-171, 1995.

MINETTE, E. Geologia de engenharia: glossário de termos técnicos. Viçcosa, U niversidade Federal de Viçosa, 1985. 43p. (Apostila, 207)

MOURA FILHO, W. Métodos de campo e laboratório: levantamento e física do solo. Viçosa, Universidade Rural do Estado de Minas Gerais, 1964. 24p.

OLIVEIRA, J .B.; J ACOMINE, P.K.Y.\& CAMARGO, M.N. Classes gerais de solos do Brasil: guia auxiliar para seu reconhecimento. 2.ed. J aboticabal, FUNEP, 1992. 201p.

RESENDE, M.; BAHIA FILHO, A.F.C. \& BRAGA, J.M Mineralogia da argila de $L$ atossolos estimada por al ocação a partir do teor total de óxidos do ataque sulfúrico. R. Bras. Ci. Solo, 11:17-23, 1987.

SANTANA, D.P. Soil formation in a toposequence of Oxisols from Patos de Minas region, Minas Gerais state, Brazil. West Lafayette, Purdue University, 1984. 129p. (Tese de Doutorado)

SCERNE, R.M.C. Estudo agrodimático do cacaueiro (Theobroma cacao L.), em Belém, PA. Viçosa, Universidade F ederal de Viçosa, 1988. 64p. (Tese de Mestrado)

SOUZA J r., J.O. Fatores edafoclimáticos que influenciam a produtividade do cacaueiro cultivado no sul da Bahia, Brasil. Viçosa, Universidade Federal de Viçosa, 1997. 146p. (Tese de Mestrado)

TORRENT, J .; SCHWERTMANN, U. \& SCHULZE, D.G. Iron oxide mineralogy of some soils of two river terrace sequences in Spain. Geoderma, 23:191-208, 1980.

YAW, A. The influence of environment on growth and production of the cacao tree: soils and nutrition. In: CONFERENCE INTERNACIONALE SUR LA RECHERCHE CACAOYERE, 7., Douala, 1979. Actes Lagos, Cocoa Producers' Alliance, 1981. p.167-176. 